\title{
22q11.2 Deletion syndrome: What the ENT surgeon needs to know about Velopharyngeal Insufficiency and its impact on Speech and Language Development.
}

Miss Victoria Blackabey and Miss Ruth Capper

Department of Otolaryngology, Doncaster Royal Infirmary, Doncaster, United Kingdom

\section{Background}

22q11.2 Deletion syndrome (22q11.2DS) occurs in 1 in 4000 live births [1] and often results in significant speech and language delay [1,2]. This is due to delay in both language and speech acquisition; the latter often contributed to by the presence of submucosal cleft palate (SMCP) and velopharyngeal insufficiency (VPI) [1]. Other features of 22q11.2DS include learning difficulties, muscle hypotonia and hypoplasia and laryngeal abnormalities, all of which can contribute to poor speech acquisition [2].

\section{Objectives}

To compare speech outcomes between different surgical techniques for SMCP and VPI repair in 22q11.2DS and non-syndromic children following cleft palate $(\mathrm{CP})$ repair.

\section{Methods}

Literature search of surgical techniques for SMCP repair and VPI surgery in 22q11.2DS. Comparison of speech outcomes for SMCP and VPI in 22q11.2DS and CP repair in non-syndromic CP.

\section{Results}

In 22q11.2DS, palatoplasty alone results in normal voice resonance in only $20 \%$ of patients [1]. Soft palate movements tend to be described as sluggish and poorly co-ordinated. Half of the remaining patients require further pharygoplasty surgery $[1,3]$. Primary pharygoplasty surgery results in normal resonance in $40-60 \%$ with further surgery required in 10-13\% [1,3]. In non-syndromic CP, palate repair before 12 months results in normal voice at 5 years in $48+/-3 \%$ and speech with no evidence of structural palatal problems in $66+/-3 \%$. Secondary surgery is reported in $20 \%$ and ongoing palatal speech issues in 17\% [4].

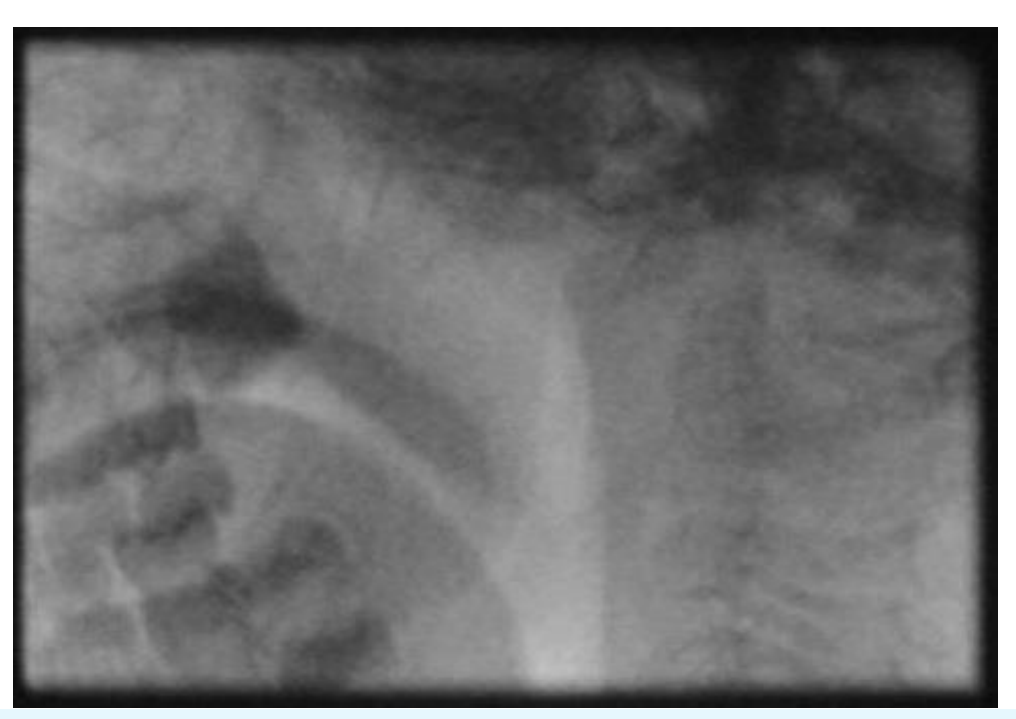

\section{Figure 1 (left).}

Rest image of a 4-year old child with 22q11.2DS

demonstrating a relatively unremarkable palate with

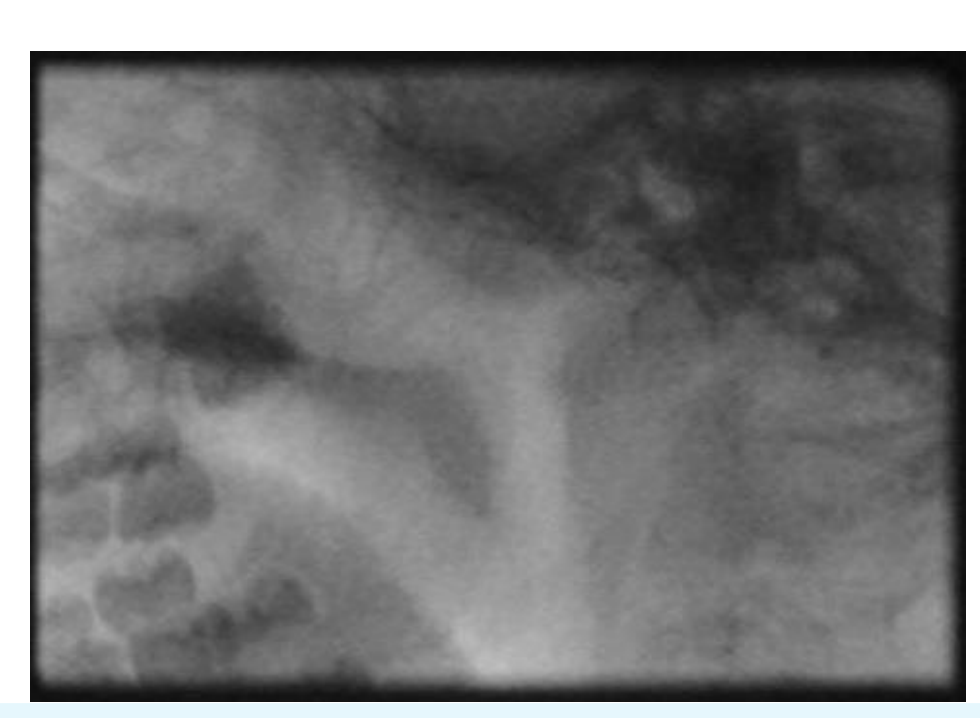

Figure 2 (left).

Shot of maximum attempted closure in the same child as Figure 1.

There is slight thinning of the anterior soft palate, a poorly defined knee (which is anterior to the ideal lift point) and a large velopharyngeal gap.

\section{Conclusions}

Speech outcomes are worse and secondary surgery more common in children with 22q11.2DS compared with nonsyndromic CP $[1,3,4]$. Hypotonia/muscle hypoplasia and subtle laryngeal abnormalities potentially contribute to poor post-operative speech outcomes in 22q11.2DS [2].

\section{References}

[1] Spruijt, N.E., ReijmanHinze, J., Hens, G., Poorten, V., Mink van der Molen., A.B., In search of the optimal Surgical treatment for velopharyngeal dysfunction in 22q11.2 Deletion Syndrome: A systematic review., 2012. PLoS, 7(1) 1-11.

[2] Solot, C.B., Gerdes, M., Kirschner, R.E., McDonald-McGinn, D.M., Moss, E., Woodin, M., Aleman, D., Zackai, E.H., Wang., P.P., Communication issues in 22q11.2 deletion syndrome: Children at risk., 2001. Genetics in Medicine, 3 (1), 67-71.

[3] Sommerlad, B.C., Surgical Management of velopharyngeal incompetence in velocardiofacial syndrome., 2004. Cleft Palate craniofacial journal, 41 (2), 124-135.

[4] Britton L, Albery L, Bowden M, Harding-Ball A, Phippen G, Sell D. A Cross-Sectional Cohort Study of Speech in Five-Year-Olds With Cleft Palate 6 Lip to Support Development of National Audit Standards. BENCHMARKING SPEECH STANDARDS IN THE UNITED KINGDOM, 2014. Cleft Palate craniofacial journal, 51(4), 431-451. 